\title{
Prevalence of Opisthorchis viverrini-Like Fluke Infection in Ducks in Binh Dinh Province, Central Vietnam
}

\author{
Thanh Thi Ha Dao ${ }^{1,2,3}$, Emmanuel Nji Abatih², Thanh Thi Giang Nguyen4, Ha Thi Lam Tran5, Sarah Gabriël2, \\ Suzanne Smit ${ }^{2}$, Phap Ngoc Le ${ }^{5}$, Pierre Dorny ${ }^{2,3, *}$ \\ ${ }^{1}$ National Institute of Veterinary Research, Hanoi, Vietnam; 'Institute of Tropical Medicine Antwerpen, 2000 Antwerp, Belgium; ${ }^{3}$ Ghent University, \\ B-9820 Merelbeke, Belgium; “Ministry of Health, Hanoi, Vietnam; ${ }^{5}$ Binh Dinh Sub-Department of Animal Health, Qui Nhon City, Binh Dinh Province, \\ Vietnam
}

\begin{abstract}
Following the first report of Opisthorchis viverrini infection in a domestic duck in Phu My District of Binh Dinh Province, Central Vietnam, many other cases were observed in the province. We determined the infection rate and intensity of $O$. viverrini infection in ducks in 4 districts of the province. A total of 178 ducks were randomly selected from 34 farms for examination of flukes in the liver and gall bladder. An infection rate of 34.3\% (range 20.7-40.4\% among districts) was found; the intensity of infection was 13.8 worms per infected duck (range 1-100). These findings show the role of ducks as a host for $O$. viverrini, duck genotype, which is sympatric with the human $O$. viverrini genotype in this province. It also stresses the need for investigations on the zoonotic potential and the life cycle of this parasite.
\end{abstract}

Key words: Opisthorchis viverrini, Opisthorchis viverrini-like fluke, duck, prevalence, Vietnam

Opisthorchiasis is a neglected tropical disease caused by the Asian liver fluke, Opisthorchis viverrini. The life cycle of $O$. viverrini involves freshwater snails and fish as intermediate hosts. Humans acquire the infection by consumption of raw or undercooked fish [1]. This hepatobiliary parasitic disease affects millions of people in the greater Mekong delta region and is linked to the development of malignant liver cancer (cholangiocarcinoma). In Thailand, where the disease has been studied extensively, the economic loss caused by opisthorchiasis is estimated at 120 million USD annually [2-4]. While dogs and cats have been identified as $O$. viverrini reservoir hosts [5], the potential role of fish-eating birds as reservoir hosts has received less attention [1]. In Vietnam, Binh Dinh Province (Fig. 1) is considered an endemic area for opisthorchiasis with an infection rate of $11.4 \%$ in humans in lowland Phu My district [6]. Interestingly, O. viverrini infection was reported in domestic ducks (Anas platyrhynchos) in this area [7]. Although morphological and genetic characteristics of the duck isolate are slightly different from those of human isolates from this area and from other endemic countries, a possible role of aquatic

\footnotetext{
- Received 23 February 2016, revised 12 April 2016, accepted 16 April 2016.

*Corresponding author (pdorny@itg.be)

(C) 2016, Korean Society for Parasitology and Tropical Medicine

This is an Open Access article distributed under the terms of the Creative Commons Attribution Non-Commercial License (http://creativecommons.org/licenses/by-nc/4.0) which permits unrestricted non-commercial use, distribution, and reproduction in any medium, provided the original work is properly cited.
}

birds as reservoir hosts for this zoonotic fluke was suggested $[7,8]$. The validity of a $O$. viverrini duck genotype has been contested $[9,10]$, but Dorny et al. [8] argued that the high identity of the ITS-2 partial sequence of the duck isolates to human isolates of $O$. viverrini justifies the classification of the duck flukes as $O$. viverrini-like. Two genotypes of a species occurring in the same endemic area and sharing the same intermediate hosts may lead to hybridization/introgression [11] and make the epidemiology of the disease more complex.

Following the first record of $O$. viverrini infection in ducks in 2009, many cases have been reported in other areas of the province, including 4 lowland districts, namely, Phu My, Phu Cat, An Nhon, and Tuy Phuoc [7]. In these districts, ducks are reared for dual purposes; meat and egg production. During the day ducks scavenge on rice-fields, irrigation canals, streams or rivers, and may feed on small freshwater fish. Infected ducks contaminate the water bodies by passing parasite eggs with their feces. In the water, prevailing Bithynia spp. snails and Cyprinid fish, 2 common intermediate hosts of O. viverrini, can complete the life cycle of this parasite. The aim of this study was to clarify the role of domestic ducks as the final hosts of $O$. viverrini by determining the prevalence and intensity of infection of O. viverrini in ducks in Binh Dinh Province. Information obtained in this study will contribute to a better understanding of the epidemiological situation of small liver fluke infections in Central Vietnam. 

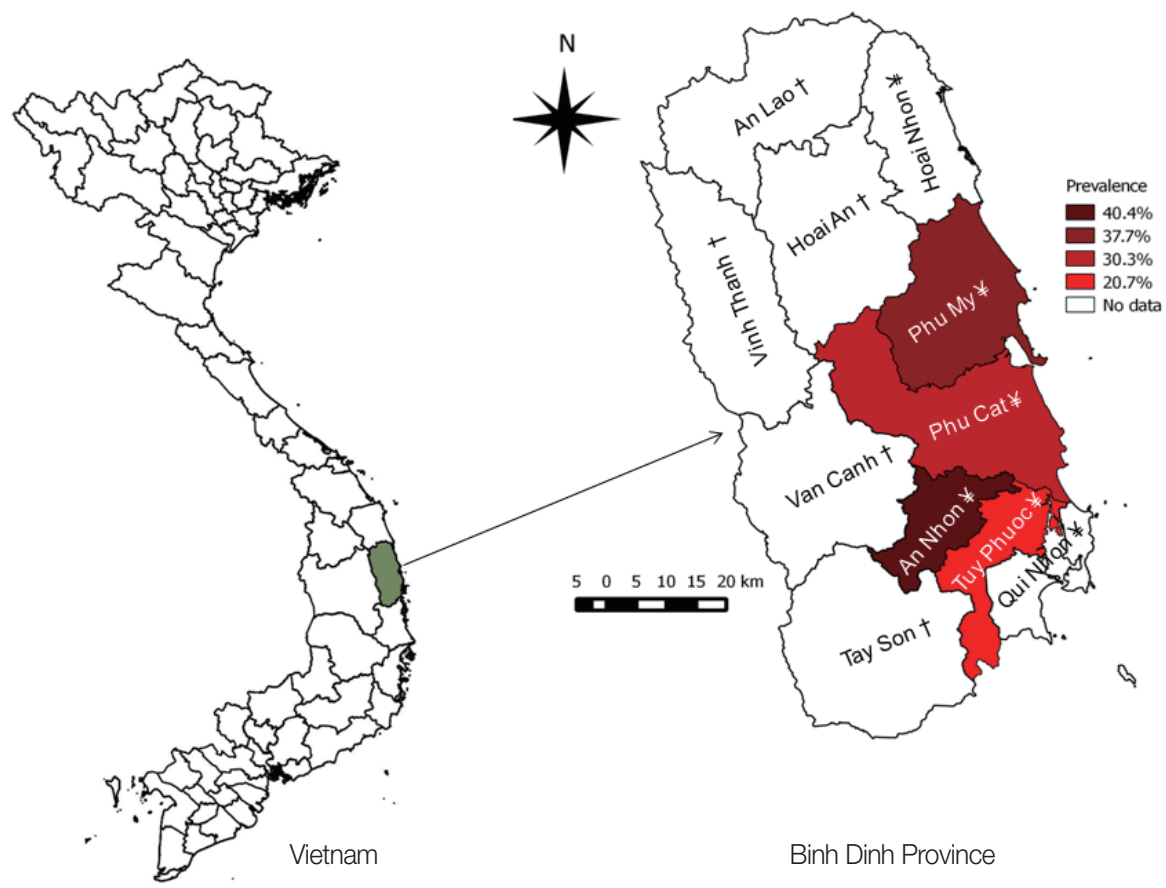

Binh Dinh Province

Fig. 1. Study areas and distribution of the prevalence of Opisthorchis viverrini infections in ducks (Anas platyrhynchos) in 4 lowland districts of Binh Dinh Province, Central Vietnam. thighland areas and $*$ lowland areas of the province.

Binh Dinh Province is located in the South central coast region of Vietnam and is composed of 11 districts, 5 of which are in the highland and 6 in the lowland along the coast (Fig. 1). Most of the population of the province lives near the coast. The annual average temperature and rainfall are $26^{\circ} \mathrm{C}$ and $1,935 \mathrm{~mm}$, respectively, with a dry season from January to August, and a rainy season from September to December. Serious flooding may occur, mostly in December as a result of tropical storms. Fresh water in the province mainly comes from 4 big rivers of which 3 rivers support fresh water for the lowlands (Latinh River in Phu My and Phu Cat districts, Kon River in An Nhon district, and Ha Thanh River in Tuy Phuoc district and Quy Nhon city). In addition, 49 artificial freshwater reservoirs support freshwater requirements during the long dry season in the province. People in the province mainly live on agriculture, including rice cultivation, raising livestock and poultry, and fish production by sea fishing and aquaculture. Ducks are mostly raised in the lowland districts, which have been reported as the endemic area of opisthorchiasis in humans and ducks. Ducks are kept on water bodies during the day and in duck houses at night where they also lay their eggs. Guided by the farmers, duck flocks are taken to water bodies in the morning; they consist of streams or rivers on which ducks scavenge in a fenced area. Only after harvest, ducks are also taken to rice fields where they can feed on seed leftovers. Ducks are fed 3-4 times/day with commercial feed. Duck production contributes to more than 45 million US dollar per year of the provincial income [12].

From December 2013 to March 2015, 34 duck-farms in districts of Phu My $\left(14.250^{\circ} \mathrm{N} 109.083^{\circ} \mathrm{E}\right)$, Phu Cat $\left(14.000^{\circ} \mathrm{N}\right.$ $\left.109.000^{\circ} \mathrm{E}\right)$, An Nhon $\left(13.917^{\circ} \mathrm{N} 109.083^{\circ} \mathrm{E}\right)$, and Tuy Phuoc $\left(13.833^{\circ} \mathrm{N} 109.167^{\circ} \mathrm{E}\right)$ were randomly selected from the registries supported by the Sub-Department of Animal Health of Binh Dinh Province. From each farm, 2-8 ducks were randomly purchased depending on the size of the flock. A total of 178 ducks from 20 communes (a lower geographical unit of district) were examined for adult worms in the liver and the gall bladder. The ducks were killed by exsanguination from the neck vein and their liver and gall bladder were removed in separate dishes containing buffered saline. The liver was opened by following the main tributaries of the biliary duct. The gall bladders were opened and turned inside out to examine for any visible worms. Next, the liver was cut into small and thin pieces, and placed in buffered saline for $5 \mathrm{~min}$, then crushed and filtered through a tea strainer. All visible flukes were collected in separate Petri dishes and washed several times with buffered saline before being counted and fixed in $70 \%$ ethanol for morphological and molecular identification. 
Forty recovered worms were randomly selected and stained with carmine dye (based on Semichon's acetic carmine 1929). Morphological identification was done using published taxonomic references on O. viverrini $[1,7]$. DNA was separately extracted from 4 fresh randomly selected worms using the Gentra Puregene Kit (Qiagen, Germantown, Maryland, USA). Two pairs of primers 3S \& BD2 [13] for ITS2 marker and COI-OvHap F \& R [14] for COI marker were used to amplify portions of the ITS2 and the COI genes, respectively. The PCR products were visualized on agarose gel 1.5\% with the Mupid ${ }^{\circledR} \_$One electrophoresis system and sequenced (University of Antwerp, Antwerp, Belgium). The obtained DNA sequences of the COI and ITS2 markers, after editing [15] were aligned to sequences of O. viverrini, which are deposited in GenBank (no. KF 557572 \& KF 557573 for the COI DNA sequence and KF 577570 \& KF 577571 for the ITS2 DNA sequence). All collected data were recorded in Excel and transferred to STATA, version 11.2, software (StataCorp LP, College Station, Texas, USA) for statistical analysis. Descriptive statistics were used to summarize the overall prevalence and the intensity of $O$. viverrini infection by district, age, production type (egg or meat produc- tion), places where ducks were scavenging, and knowledge of the duck owners on the small liver fluke infection of their ducks.

Table 1. Opisthorchiasis in ducks and related information in Binh Dinh province

\begin{tabular}{llrcr}
\hline Factor & Category & $\begin{array}{c}\text { No. } \\
\text { examined }\end{array}$ & $\begin{array}{c}\text { Apparent } \\
\text { prevalence (\%) }\end{array}$ & $\begin{array}{c}\text { 95\% } \\
\text { Cl (\%) }\end{array}$ \\
\hline Total & & 178 & 34.3 & $27-42$ \\
District & Phu My & 69 & 37.7 & $26-50$ \\
& Phu Cat & 33 & 30.3 & $16-49$ \\
& An Nhon & 47 & 40.4 & $26-56$ \\
& Tuy Phuoc & 29 & 20.7 & $8-40$ \\
\hline Age & $<3$ months & 76 & 14.5 & $7-24$ \\
& 3-12 months & 47 & 42.6 & $28-58$ \\
& $>12$ months & 55 & 54.5 & $41-68$ \\
Type of & Meat & 72 & 16.7 & $9-27$ \\
production & Eggs & 106 & 46.2 & $36-56$ \\
Scavenging on & Rice field & 166 & 34.3 & $27-42$ \\
& River & 73 & 34.2 & $24-46$ \\
& Stream & 75 & 44.0 & $33-56$ \\
& Irrigation canal & 159 & 37.7 & $30-46$ \\
Knowledge $^{\mathrm{a}}$ & Yes & 61 & 50.8 & $38-64$ \\
& No & 117 & 25.6 & $18-35$ \\
\hline
\end{tabular}

$\mathrm{Cl}$, confidence Intervals.

aknowledge of duck owner on opisthorchiasis in their ducks.
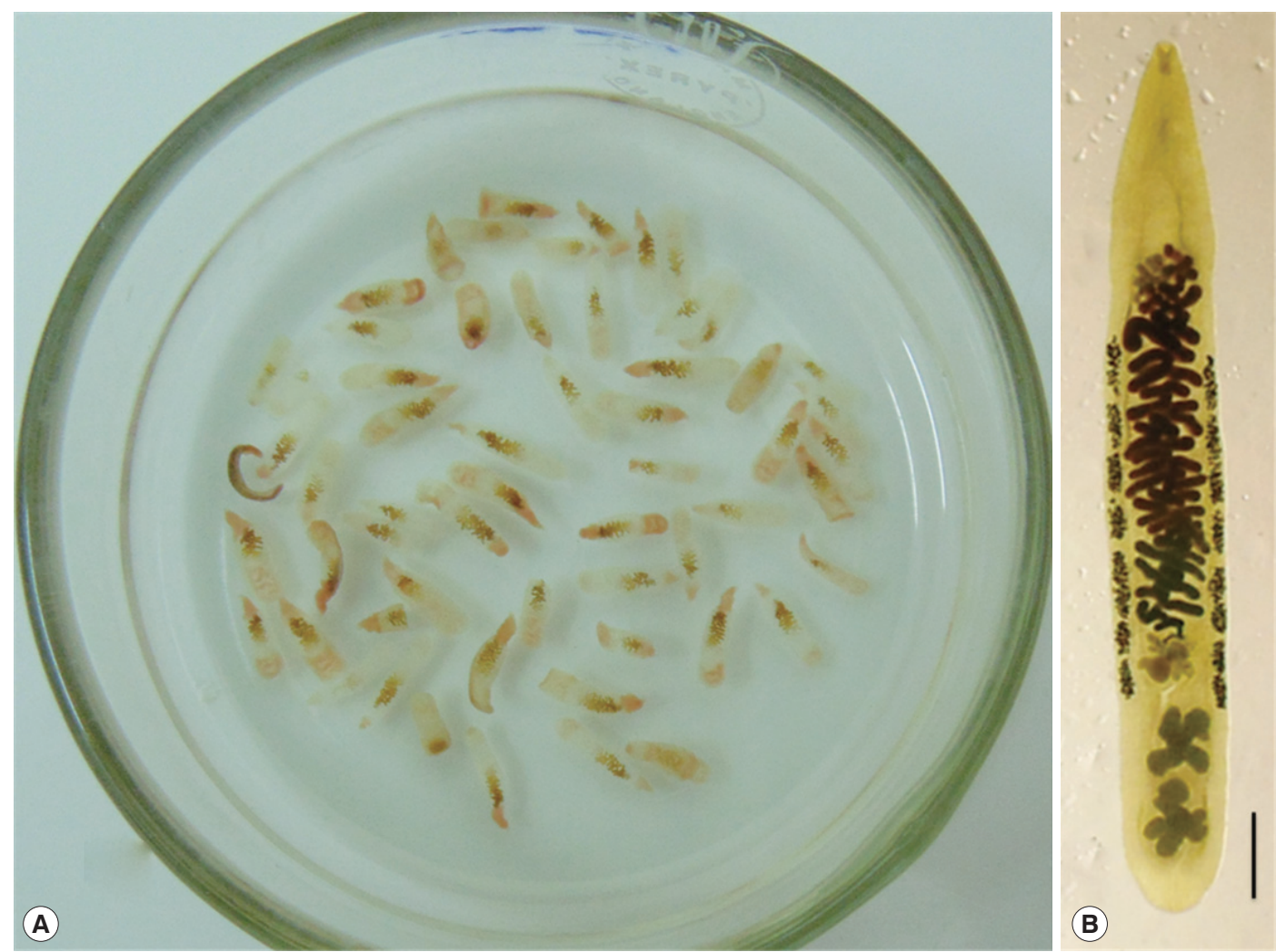

Fig. 2. Worms recovered from domestic ducks (Anas platyrhynchos) in Binh Dinh Province, Central Vietnam. (A) Worms recovered from the liver. (B) Worm recovered from the gall bladder, unstained. Scale bar $=1 \mathrm{~mm}$. 


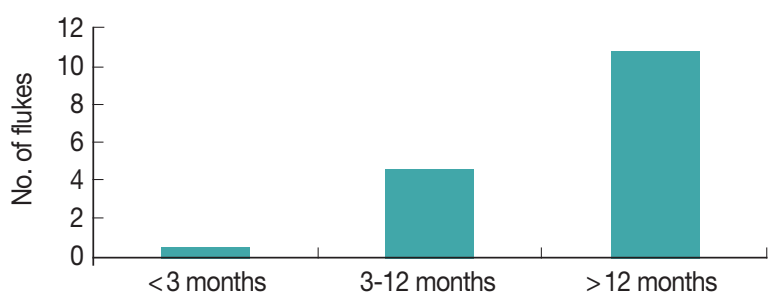

Fig. 3. Average intensity of Opisthorchis viverrini infection in ducks in function of age.

Small liver fluke infection was found in the liver and gall bladder of 61 ducks from 178 ducks examined, with the number of worms recovered per duck ranging from 1 to 100 . The overall infection rate of $O$. viverrini infection was $34.3 \%$ (Table 1) and the mean intensity of worms recovered was 13.8 worms/positive duck. The worms were morphologically identified as O. viverrini duck type (Fig. 2), with larger testes in comparison with those of the O. viverrini human type [7]. The ITS2 DNA sequences of the worms (no. KT 894940, KT 894941, KT 894942, and KT 894943) were 100\% identical to those of the O. viverrini duck genotype (no. KF 577570, KF 577571). Furthermore, the COI sequences of the recovered worms (no. KT 894944, KT 894945, KT 894946, and KT 894947) were identical to the COI DNA sequences (no. KF 577572, KF 577573) of the O. viverrini duck genotype at 99.7\% (1 nucleotide differences) and 98.8\% (4 nucleotides difference), respectively from 322 compared nucleotides. Ducks in An Nhon district were the most infected (40.4\%) with the highest intensity (mean no. of worms $=18.9$ /positive duck). The prevalence and intensity of $O$. viverrini infection in ducks reared for egg production were much higher (46.2\%; 16.4 worms/positive duck) than those of ducks for meat production (16.7\%; 3.4 worms/positive duck). It was also observed that the prevalence and intensity of infection was significantly higher in older ducks (Fig. 3). Ducks scavenging on streams were the most infected (44\%) whereas ducks scavenging on rivers presented the highest mean intensity of 17.3 worms/positive duck.

The prevalence of O. viverrini of $34.3 \%$ was high when compared to the infection rate of humans with O. viverrini [4], which is considered low if $<10 \%$, moderate if $=10-15 \%$, or high if $>15 \%$. Because of its dependence on freshwater bodies, the domestic duck can feed on small freshwater fish, which might be highly infected with fishborne zoonotic trematodes $[16,17]$. The role of ducks as reservoir hosts of some zoonotic small intestinal flukes was confirmed [18], and its infection with O. viverrini (small liver fluke) was reported [7]. Although the zoonotic potential of the O. viverrini duck genotype has yet to be confirmed [8], the high prevalence and intensity of $O$. viverrini in ducks indicate that large numbers of parasite's eggs are spread into water bodies on which ducks scavenge every day. These eggs can be dispersed with water to wide geographical areas by the strong flow of streams, irrigation canals, and by annual flooding of rice fields or rivers. The 2 kinds of $O$. viverrini intermediate hosts, Bithynia snails and cyprinid fish are highly abundant in all freshwater bodies in lowland districts of the province (unpublished results). Infection of a Bithynia snail with a single $O$. viverrini egg can result in shedding of up to 27,692 O. viverrini cercariae during 2 months [19]. This presents the parasite with favourable conditions for completing its life cycle and explains why both prevalence and intensity of infection were high in the 4 investigated districts. Keeping ducks on rivers was associated with a significantly higher intensity of $O$. viverrini infection in ducks compared to other places $(P<0.001)$. During the dry season, streams, rice fields, and irrigation canals dry out while there is still water in rivers. Ducks therefore tend to scavenge more on rivers during this period in which small freshwater fish are present with the highest intensity of O. viverrini infection [20]. In addition, infection of ducks with the liver fluke is an accumulative infection. Both the prevalence and intensity of $O$. viverrini infection in ducks were increased as the age of ducks increased (Fig. 3). The accumulative infection can also explain the higher prevalence and intensity of infection of ducks for egg production in comparison with those of ducks for meat production. Ducks for meat purpose are sold on the local markets at the age of 3 months and as a result are only briefly exposed to infection. In contrast, ducks for egg production are culled at the age of 2 years, allowing them a much longer exposure. The significant positive relationship between knowledge of $O$. viverrini infection in ducks and prevalence (Table 1) can be explained by the fact that more farmers who raise ducks for eggs know about the infection than duck meat farmers. Some duck egg farmers treat their ducks with praziquantel, which may explain the lower intensity of infection in this group.

In conclusion, while Binh Dinh Province in Central Vietnam was confirmed as an endemic area of $O$. viverrini human genotype [6], the findings of the present study confirmed this area to be hyperendemic of the O. viverrini duck genotype. The co-existence of 2 O. viverrini genotypes in an endemic area, probably sharing the same intermediate hosts may render the 
epidemiological status of opisthorchiasis more complex. The sympatric occurrence of $O$. viverrini human and duck genotypes in Binh Dinh Province may result in hybridization or introgression between these 2 genotypes. Evidence of hybridization/introgression among species in the same genus was found in zoonotic Fasciola gigantica in Vietnam [11]. More studies on the genome and epidemiology of these $2 \mathrm{O}$. viverrini genotypes and on the intermediate hosts in Binh Dinh Province should be performed for a better understanding of this cryptic parasite.

\section{ACKNOWLEDGMENTS}

This study was financially supported by the Directorate General for Development Cooperation (DGD)-PhD Program, Belgium. The authors would like thank the staff of the Sub-Animal Health Department of Binh Dinh Province, Vietnam, the staff of the Biomedical Science Department of ITM, Belgium, Brecht Devleesschauwer from Ghent University, Belgium, and Samson Leta from Gondar University, Ethiopia for their logistic and technical help.

\section{CONFLICT OF INTEREST}

The authors report no conflict of interest related to this work.

\section{REFERENCES}

1. Kaewkes S. Taxonomy and biology of liver flukes. Acta Trop 2003; 88: 177-186.

2. Sripa B, Kaewkes S, Sithithaworn P, Mairiang E, Laha T, Smout M, Pairojkul C, Bhudhisawasdi V, Tesana S, Thinkamrop B, Bethony JM, Loukas A, Brindley PJ. Liver fluke induces cholangiocarcinoma. PLoS Med 2007; 4: e201.

3. Andrews RH, Sithithaworn P, Petney TN. Opisthorchis viverrini: an underestimated parasite in world health. Trends Parasitol 2008; 11: 497-501.

4. Sithithaworn $P$, Andrews RH, Nguyen VD, Wongsaroj T, Sinuon M, Odermatt P, Nawa Y, Liang S, Brindley PJ, Sripa B. The current status of opisthorchiasis and clonorchiasis in the Mekong Basin. Parasitol Int 2012; 61: 10-16.

5. Aunpromma S, Tangkawattana P, Papirom P, Kanjampa P, Tesana S, Sripa B, Tangkawattana S. High prevalence of Opisthorchis viverrini infection in reservoir hosts in four districts of Khon Kaen Province, an opisthorchiasis endemic area of Thailand. Parasitol Int 2012; 61: 60-64.
6. Dao THT, Bui VT, Abatih E, Gabriël S, Nguyen TG, Huynh HQ, Nguyen VC, Dorny P. Opisthorchis viverrini infections and associated risk factors in a lowland area of Binh Dinh Province, Central Vietnam. Acta Trop 2016; 157: 151-157.

7. Dao TH, Nguyen TG, Victor B, Gabriël S, Dorny P. Opisthorchis viverrini-like liver fluke in birds from Vietnam: morphological variability and $\mathrm{rDNA} / \mathrm{mtDNA}$ sequence confirmation. J Helminthol 2014; 88: 441-446.

8. Dorny P, Dao T, Victor B, Nguyen T, Gabriël S. Response to manuscript 'Is Opisthorchis viverrini an avian liver fluke?'. J Helminthol 2015; 89: 257-258.

9. Nawa Y, Doanh PN, Thaenkham U. Is Opisthorchis viverrini an avian liver fluke? J Helminthol 2015; 89: 255-256.

10. Doanh PN, Nawa Y. Clonorchis sinensis and Opisthorchis spp. in Vietnam: current status and prospects. Trans R Soc Trop Med Hyg 2016; 110: 13-20.

11. Le TH, De NV, Agatsuma T, Nguyen TG, Nguyen QD, McManus DP, Blair D. Human fascioliasis and the presence of hybrid/introgressed forms of Fasciola hepatica and Fasciola gigantica in Vietnam. Int J Parasitol 2008; 38: 725-730.

12. Binh Dinh Statistical Office. Livestock report. Form No. 009.S/ BCC-NLTS. 2015.

13. Bowles J, Hope M, Tiu WU, Liu X, McManus DP. Nuclear and mitochondrial genetic markers highly conserved between Chinese and Philippine Schistosoma japonicum. Acta Trop 1993; 55: 217-229.

14. Thaenkham U, Nuamtanong S, Vonghachack Y, Yoonuan T, Sanguankiat S, Dekumyoy P, Prommasack B, Kobayashi J, Waikagul J. Discovery of Opisthorchis lobatus (Trematoda: Opisthorchiidae): a new record of small liver flukes in the Greater Mekong Sub-region. J Parasitol 2011; 97: 1152-1158.

15. Hall TA. BioEdit: a user-friendly biological sequence alignment editor and analysis program for Windows 95/98/NT. Nucleic Acids Symp Ser 1999; 41: 95-98.

16. Nguyen MH, Do TD, Nguyen LA, Phan TV, Bui NT, Nguyen VH, Hoang VH, Le XC. Current status of fish-borne zoonotic trematode infections in Gia Vien district, Ninh Binh province, Vietnam. Parasit Vectors 2015; 8: 21.

17. Thu ND, Dalsgaard A, Loan LT, Murrell KD. Survey for zoonotic liver and intestinal trematode metacercariae in cultured and wild fish in An Giang Province, Vietnam. Korean J Parasitol 2007; 45: 45-54.

18. Nguyen LA, Madsen H, Dalsgaard A, Nguyen TP, Dao THT, Murrell KD. Poultry as reservoir hosts for fishborne zoonotic trematodes in Vietnam fish farms. Vet Parasitol 2010; 169: 391-394.

19. Phongsasakulchoti P, Sri-aroon P, Kerdpuech Y. Emergence of Opisthorchis viverrini cercariae from naturally infected Bithynia (Digoniostoma) siamensis goniomphalos. Southeast Asian J Trop Med Public Health 2005; 36: 189-191.

20. Dung VT, Waikagul J, Thanh BN, Vo DT, Nguyen DN, Murrell KD. Endemicity of Opisthorchis viverrini liver flukes, Vietnam, 2011-2012. Emerg Infect Dis 2014; 20: 152-154. 
